\section{Unconscious perception at the objective detection threshold exists}

\author{
MICHAEL SNODGRASS \\ University of Michigan Medical Center, \\ Ann Arbor, Michigan \\ EDWARD BERNAT \\ University of Minnesota, Minneapolis, Minnesota \\ and \\ HOWARD SHEVRIN \\ University of Michigan Medical Center, \\ Ann Arbor, Michigan
}

Does unconscious perception at the objective detection threshold (ODT) exist? In this reply, formal meta-analyses of previously narratively reviewed evidence (Snodgrass, Bernat, \& Shevrin, 2004) provide strong evidence for large, reliable unconscious perceptual effects, and further strengthen previous conclusions for their ODT status. These meta-analyses dispel general concerns that ODT effects are small, unreliable, or susceptible to file drawer concerns (cf. Reingold, 2004). Furthermore, the specific objections (Holender \& Duscherer, 2004) to individual ODT effects are refuted, and objections to our proposed solutions to the exhaustiveness, exclusiveness, and null sensitivity problems (Haase \& Fisk, 2004; Reingold, 2004) are shown to be inapplicable, contradicted by the available evidence, or both. Accordingly, the strong evidence for ODT effects, taken together with the nonmonotonic relationship, contradicts the single-process conscious perception model (e.g., Holender \& Duscherer, 2004) and provides stronger evidence for unconscious perception than hitherto available.

We thank Haase and Fisk (2004), Reingold (2004), and Holender and Duscherer (2004) for their thoughtful commentaries, which, along with our target article, reflect very different positions. On the one hand, Holender and Duscherer are convinced that unconscious perception does not exist, and favor the single-process conscious perception model. Haase and Fisk (2004) are also skeptical, though more neutral. Nonetheless, these commentaries agree that the objective threshold/strategic model (Snodgrass, Bernat, \& Shevrin, 2004) is superior to the subjective threshold

This research was undertaken as part of a research program on conscious and unconscious processes in the Ormond and Hazel Hunt Memorial Laboratory, directed by H.S. and supported by gifts from Robert Berry and the Smart Family Foundation. Special thanks to Mark Van Selst and Philip Merikle for making their raw data available. Correspondence concerning this article should be addressed to M. Snodgrass, Department of Psychiatry, University of Michigan, 2101 Commonwealth, Suite B, Ann Arbor, MI 48105 (e-mail: jmsnodgr@umich.edu).

Note-This article was accepted by the previous editorial team, headed by Neil Macmillan. (e.g., Merikle \& Daneman, 1998) and objective threshold/ rapid decay (e.g., Draine \& Greenwald, 1998) models, and that it ultimately may be capable of demonstrating unconscious perception. ${ }^{1}$ In contrast, Reingold (2004) suggests that our proposal makes no progress, argues that objective threshold effects do not exist, and reiterates Reingold and Merikle's (1990) analysis and proposed solutions. ${ }^{2}$ Finally, we argue that there is strong evidence for unconscious perception at the objective detection threshold (ODT), and further that the absence of effects at the longer objective identification threshold (OIT) and the reappearance of effects above the OIT suggest a nonmonotonic relationship with important methodological and theoretical implications.

In much of what follows, we will address various specific empirical and methodological issues. We emphasize at the outset, however, that broader issues fundamental to consciousness studies in general are at stake-indeed, nothing less that the structure and scope of the mind itself. Are representational mental processes necessarily conscious, or do they take unconscious form as well? And if the latter is so, what are their respective functions, and how do they interact? These issues have never been more crucial, particularly with the increasing involvement of neuroscience - thus putting our understanding of the brain as well as the mind in play.

The commentaries raise (1) challenges to the literature review; (2) challenges to the methodological framework; and (3) theoretical and philosophical objections. In our view, the commentaries raise no serious objections to the objective threshold/strategic model.

\section{What Do the Data Show?}

We and all three commentaries agree that null findings obtain at the OIT, and that beyond the OIT, effects are positively related to stimulus intensity. ${ }^{3}$ The major ostensibly unsettled empirical issue, then, is whether reliable ODT effects exist. This issue really involves two questions: (1) Do reliable, sizable unconscious perception index effects exist? And (2) are the conscious perception index effects (here, SDT detection) really zero? In our target article, we addressed these questions through a narrative review; here, we meta-analyze the same empirical evidence (Carr \& Dagenbach, 1990; Dagenbach, Carr, \& Wilhelmsen, 1989; Greenwald, Klinger, \& Liu, 1989; Groeger, 1988; Klinger \& Greenwald, 1995; Price, 1990; Snodgrass \& Shevrin, 2002; Snodgrass, Shevrin, \& Kopka, 1993; Van Selst \& Merikle, 1993). ${ }^{4}$ Such quantitative meta-analyses allow precise answers to certain questions raised by the commentaries.

\section{Unconscious Perception Index Meta-Analysis}

Using Rosenthal and Rosnow's (1991) procedures, we calculated Cohen's $d$ for the dependent variables (e.g., indirect semantic priming, direct higher level discriminations) from each of the 20 independent samples used in the 
nine investigations just cited. Usually, $d$ was derived from the relevant $t$ or $F$ tests. $^{5}$

Results. The meta-analytic findings are presented in the first column of Table 1. The mean Cohen's $d$ was .884, a large effect according to Cohen's widely used criteria $(.20=$ small; $.50=$ medium; $.80=$ large $)$; furthermore, the weighted and median $d \mathrm{~s}$ are also large. These findings clearly refute Reingold's (2004) claim that the effects' magnitude is "extremely small." Moreover, the obtained $d$ is very reliable. Stouffer's combined $Z$ provides the fixed effects approach significance level, whereas the onesample $t$ provides the random effects approach significance level. As Rosenthal (1995) explained, the former takes individual participants as the unit of analysis and indexes generalizability to other participants in similar experimental paradigms. The latter, on the other hand, takes studies as the unit of analysis and indexes generalizability to all studies from the same population (here, ODT studies in general). In the present meta-analysis, both the combined $Z$ and the one-sample $t$ are highly significant. The latter finding is particularly meaningful, because it indicates that the present findings are indeed generalizable to other, nonsampled ODT studies, whether they have used paradigms similar to or different from those included here. These findings, as well as the substantial fail-safe $N(899)$, suggest that replicability and file drawer concerns (Reingold, 2004) are minimal.

Furthermore, chi-square heterogeneity tests for both effect sizes and significance levels were nonsignificant, suggesting that the present sample is from one population and that the mean $d$ is representative. To facilitate further examination, individual effect sizes are presented in the first column of Table 2. Notwithstanding the nonsignificant heterogeneity tests, inspection of Table 2 suggests two perhaps unusually high effect sizes $(d \mathrm{~s}=1.83$; from Groeger, 1988, and Van Selst \& Merikle, 1993, Experiment 1). Excluding these two studies yielded quite similar findings: mean Cohen's $d=.779, d_{S D}=.318, d_{S E M}=$ $.075 ; 95 \%$ CI, .621-.937; Stouffer's combined $Z=10.38$ $\left(p<1.0 \times 10^{-31}\right)$; one-sample $t(17)=10.39(p=4.39 \times$ $\left.10^{-9}\right)$. Essentially, the only difference from the original meta-analysis is the slightly lower mean Cohen's $d$, which is now quite close to the original weighted and median $d$ s. Finally, the unpublished ( $k=5$; Price, 1990; Snodgrass \& Shevrin, 2002) and published ( $k=15$; all other studies) samples had virtually identical effect sizes (mean $d$ s were .90 and .88 , respectively), indicating that this factor did not affect the results.

\section{Conscious Perception Index Meta-Analysis}

Cohen's $d$ for detection was calculated with sample means and standard deviations ( $S D \mathrm{~s})$ wherever possible. When $S D$ s were not provided, they were estimated from the binomial distribution given the number of detection trials. ${ }^{6}$ In this way, $d$ was calculated for each of the 12 independent samples that provided sufficient information. This was not possible in all 20 samples for either of two reasons: (1) Although threshold estimation procedures were performed initially, final ODT retest results were not reported in detail (Dagenbach et al., 1989, Experiments 1-3; Greenwald et al., 1989, Experiment 1); or (2) ODT status was assessed in separate experiments (i.e., in Snodgrass \& Shevrin, 2002, Experiment 3, but not Experiments 1 and 2; similarly for Snodgrass et al., 1993; and Van Selst \& Merikle, 1993). Importantly, however, each of the nine investigations included in the unconscious perception metaanalysis contributed at least one detection sample to the conscious perception meta-analysis. Furthermore, avail-

Table 1

Meta-Analytic Results

\begin{tabular}{lcc}
\hline & \multicolumn{2}{c}{ Effects } \\
\cline { 2 - 3 } \multicolumn{1}{c}{ Measure } & $\begin{array}{c}\text { Unconscious Perception Index } \\
\text { (e.g., priming; } k=20)\end{array}$ & $\begin{array}{c}\text { Conscious Perception Index } \\
\text { (SDT detection; } k=12)\end{array}$ \\
\hline Cohen's $d$ & .884 & .070 \\
$d_{S D}$ & .442 & .228 \\
$d_{S E M}$ & .099 & .066 \\
$95 \%$ CI & $.677 \leq d \leq 1.09$ & $-.075<d<.215$ \\
Stouffer's & $11.15, p<1.0 \times 10^{-31}$ & $.857, p=.196$ \\
$\quad$ combined $Z$ & $t(19)=8.94, p=1.54 \times 10^{-9}$ & $t(11)=1.065, p=.155$ \\
One-sample $t$ & .746 & .064 \\
Weighted $d$ & .768 & .091 \\
Median $d$ & $\chi^{2}(19)=24.72, .10<p<.20$ & $\chi^{2}(11)=7.55, .70<p<.80$ \\
Heterogeneity & & \\
$\quad$ of effect size & $\chi^{2}(19)=14.89, .70<p<.80$ & $\chi^{2}(11)=2.97, .99<p<.995$ \\
Heterogeneity & 899 & - \\
$\quad$ of significance & 23.9 & 24.42 \\
Fail-safe $N$ & &
\end{tabular}

Note $-k=$ number of samples. The standard deviations, standard errors, and $95 \%$ confidence intervals of $d \mathrm{~s}$ were computed using the (conservative) random-effects approach. $p$ values for Stouffer's combined $Z$ s and onesample $t \mathrm{~s}$ are one-tailed. Weighted $d \mathrm{~s}$ are weighted by $d f$ alone (unconscious perception index) or both $d f$ and the number of detection trials (conscious perception index). Heterogeneity tests are from Rosenthal and Rosnow (1991, pp. 500-501). 
Table 2

Stem-and-Leaf Displays of Unconscious and Conscious Perception Index Effect Sizes

\begin{tabular}{rcc}
\hline & $\begin{array}{c}\text { UPI Leaf } \\
\text { Stem }\end{array}$ & $\begin{array}{c}\text { CPI Leaf } \\
\text { (e.g., priming; } k=20)\end{array}$ \\
\hline 1.8 & 3,3 & \\
1.7 & & \\
1.6 & & \\
1.5 & & \\
1.4 & & \\
1.3 & $(2),(2), 6$ & \\
1.2 & 2,8 & \\
1.1 & & \\
1.0 & $(0), 4$ & \\
.9 & 0 & \\
.8 & 3,4 & \\
.7 & $(0)$ & \\
.6 & $0,7,7,(8)$ & \\
.5 & 3 & 8 \\
.4 & 5 & 3,4 \\
.3 & 9 & 7,9 \\
.2 & & $6,9,9$ \\
.1 & & 4,6 \\
+.0 & & 2 \\
-.0 & & 9 \\
-.1 & & \\
-.2 & & \\
-.3 & & \\
\hline
\end{tabular}

Note-UPI, unconscious perception index; CPI, conscious perception index. UPI effect sizes in parentheses are from Price (1990) and Snodgrass and Shevrin (2002), thus far unpublished. Published versus unpublished effect sizes were of equal magnitude; see text.

able detection performance invariably closely approximated the ODT, suggesting that these investigations' other experiments also closely approximated the ODT. ${ }^{7}$

All in all, the 20 experiments included in the unconscious perception meta-analysis yielded 10 conscious perception index effects from the same participants; in addition, 2 more such effects were available from separate experiments conducted under identical conditions (Snodgrass et al., 1993, Experiment 3; Van Selst \& Merikle, 1993, Experiment 3), making 12 in all. ${ }^{8}$

Results. The meta-analytic results are presented in the second column of Table 1 . The mean Cohen's $d$ was .07, a very small effect. Crucially, neither Stouffer's combined $Z$ nor the one-sample $t$ approached significance, suggesting that overall detection did not exceed chance. The nonsignificant combined $Z$ is particularly compelling, because the fixed effects approach is very sensitive to any deviation from chance. Moreover, the weighted $d$ is comparable. Furthermore, both the heterogeneity tests and the stemand-leaf display of detection effect sizes (see the second column of Table 2) give no indication of outliers.

One can translate the obtained mean $d$ into perhaps more familiar percentage correct (PC) units, but this requires care because it depends on the number of trials, which affects the raw $S D$. In the present meta-analysis, the mean number of detection trials per participant per study is 95 , which yields an $S D$ (by the binomial) of 4.87 . The equivalent mean $\mathrm{PC}$ is then $[47.5+(.07 * 4.87)] / 95=$ $50.36 \%$.
Implications for the null sensitivity problem. The usual concern, reiterated by Reingold (2004) and Haase and Fisk (2004), is that true detection sensitivity may actually exceed zero even when obtained sensitivity is zero due to intrinsic measurement error. Given its enhanced power, the current meta-analysis reduces this concern considerably: In translated PC units, the 95\% CI $=49.62 \%-$ $51.10 \%$, quite a narrow range. Accordingly, this metaanalysis provides solid evidence that the ODT was indeed achieved in these studies, substantially alleviating null sensitivity concerns.

Is the conscious perception meta-analysis representative? Because this meta-analysis included only half of the experiments included in the unconscious perception meta-analysis, detection performance could conceivably have exceeded chance in the nonincluded experiments. Although this seems unlikely given the collateral evidence above, if this were the case, the obtained unconscious perception mean $d$ could be artifactually inflated by nonODT experiments. Accordingly, we tested this skeptical scenario's prediction that the unconscious perception $d$ should be higher for nonincluded than for included experiments. The reverse turned out to be true; mean $d$ for nonincluded experiments $(k=10)$ was .86 , whereas mean $d$ for included experiments $(k=10)$ was .91 , thus indicating that the conscious perception meta-analysis was indeed representative.

\section{Objections to Particular Unconscious Perception Effects}

The commentators raised several specific criticisms of the reviewed evidence. Holender and Duscherer (2004), for example, suggested that Greenwald et al.'s (1989) results were likely not genuine because various investigators using related paradigms have found null results under OIT conditions. However, our review suggests precisely that unconscious perceptual findings obtain readily at the ODT but not at the OIT; crucially, Greenwald et al.'s (1989) experiments were at the former, not the latter. Accordingly, this criticism appears irrelevant.

Holender and Duscherer (2004) also argued that Kahan's (2000) retrospective prime clarification theory can explain Carr and associates' (Carr \& Dagenbach, 1990; Dagenbach et al., 1989) inhibitory priming effects without postulating center-surround processes. We doubt this, mainly because Kahan's experiments were not conducted under subliminal conditions. ${ }^{9}$ This is important because Kahan's own account (pp. 1395, 1407) suggests that retrospective clarification mechanisms should operate only when primes are partially visible, not under ODT conditions similar to those in Carr and associates' experiments. In contrast, the center-surround mechanism can operate under ODT conditions (Carr \& Dagenbach, 1990, p. 342). More importantly, this whole issue is irrelevant because our review concerned Carr and associates' positive ODT findings, not their inhibitory ODT findings. The former findings, unquestioned by Holender and Duscherer (2004), are the crucial ones. 
Finally, Holender and Duscherer (2004) suggested that Whittlesea and Price's (2001) skeptical reinterpretation of the subliminal mere exposure effect (SME; see, e.g., Kunst-Wilson \& Zajonc, 1980) applied to the pop/look experiments (e.g., Snodgrass \& Shevrin, 2002), undermining their unconscious status. Regarding the SME, Whittlesea and Price (2001) have suggested that recognition instructions engage ineffective, detail-oriented analytic response strategies, whereas preference instructions encourage more effective nonanalytic global impression strategies. Accordingly, nonanalytic strategies may simply access weakly conscious information better than analytic ones do.

In our paradigm, Whittlesea and Price's (2001) theory predicts that performance should be better under pop (nonanalytic) than under look (analytic) instructions (i.e., a pop $>$ look main effect). Notably, however, essentially the opposite obtains: The core preference $\times$ strategy interaction is carried almost entirely by the lookers, who perform better under look than under pop instructions - the reverse of Whittlesea and Price's predicted pattern. Moreover, lookers perform below, not at, chance under pop instructions. This inhibition effect provides an additional, independent contradiction of their theory, which predicts only facilitatory or null effects. Accordingly, although troublesome for SME paradigms, their account does not undermine the unconscious status of pop/look findings.

\section{Challenges to the Methodological Framework \\ The Exhaustiveness Problem}

In our target article, we discussed much evidence suggesting that identification simply is multidimensional detection, and hence that above chance identificationdependent effects should not be possible when detection $d^{\prime}=0$. If so, SDT detection is relevantly exhaustive, and reliable ODT effects thereby imply unconscious perception. We also cited various studies which indicate that ODTs are below OITs, perhaps because nondiscriminative lower level information (e.g., darkness) can support detection but not identification. In contrast, Holender and Duscherer (2004) suggest that certain masking contexts may somehow render OITs below ODTs, and hence that detection is not exhaustive after all. Haase and Fisk (2004) raise similar concerns, in particular suggesting that participants may adopt different (and less effective) strategies in detection as opposed to identification tasks, especially when they are performed in separate runs. Both these commentaries also cite Duncan (1985), who made similar speculations.

These skeptical concerns, however, lack empirical foundation. Indeed, using simultaneous detection and identification paradigms, Haase and associates (Haase \& Fisk, 2001; Haase, Theios, \& Jenison, 1999) have themselves provided much evidence supporting the multidimensional detection model, with no indication that different, less effective strategies are adopted in detection tasks. Furthermore, Thomas's (1985) extensive review yielded a "Euclidean model" essentially identical to the SDT multidimensional model. Accordingly, much hangs on Haase and Fisk's (2004) claim that identification is higher than predicted by theory when the two tasks are performed in separate runs. However, their ostensibly supportive citation (Macmillan \& Creelman, 1991; presumably pp. 130-131) concerns comparing performance on single- versus two-interval versions of the same task, not single-interval detection versus single-interval identification, which is at issue here. In contrast, when this comparison is made, all available evidence suggests that detection exceeds chance under conditions where identification does not (i.e., the latter is worse, not better, than predicted by theory), whether the two tasks are indexed in separate (Dagenbach et al., 1989; Price, 1990, Experiment 1) or simultaneous (Haase, 1994, Experiment 3A; see also pp. 76-77) runs. Thus, ODTs are below OITs either way, suggesting that participants do not use different, less effective response strategies when performing detection separately. Indeed, these data, which include both backward masking (Dagenbach et al., 1989; Price, 1990) and forward plus backward masking (Haase, 1994, p. 76) paradigms, directly contradict Duncan's (1985) and Holender and Duscherer's (2004, note 6) hypothetical scenarios, respectively.

\section{The Exclusiveness Problem}

Reingold (2004, p. 885) argues that we do not solve the exclusiveness problem, but "merely assume it away." On the contrary, we did not assume functional exclusivity, but rather inferred it from the data pattern suggested by the literature - namely, the U-shaped nonmonotonic relationship. As we said in the target article (Snodgrass et al., 2004), "Our review of the evidence suggests a third explanation [i.e., of the data pattern; emphasis added]: Conscious and unconscious perceptual influences are functionally exclusive" (p. 855). That is, our unconscious perception model was developed in response to and based upon the extant empirical evidence, just as the other models were. Furthermore, the exclusiveness problem predicts a positive relationship between the conscious and unconscious perception indexes, and it tacitly assumes that redundancy or independence relationships (cf. Jones, 1987) hold between conscious and unconscious perceptual influences. This prediction is contradicted by the negativegoing ODT-OIT portion, which instead implies at least functional exclusivity. Thus, the exclusiveness problem can and should be resolved by empirical evidence; assumptions are unnecessary. Furthermore, Reingold's suggestion that unconscious influences might still be severely reduced at the ODT, even given functional exclusivity, is contradicted by the meta-analyses, which yielded large, reliable ODT effects.

At the same time, we agree that the negative relationship in the ODT-OIT region does not demand an interpretation in terms of conscious influences on detection. Rather, when overall detection $d^{\prime}$ is essentially zero, negative relationships could instead mean that unconscious 
influences on the (nominally) conscious and unconscious perception indexes are negatively related. ${ }^{10}$ We think this possible because, contra Reingold's (2004) assertion, we do not believe that detection is exclusively sensitive to conscious perceptual influences, but that it is also sensitive to unconscious influences when conscious perception is absent. Moreover, unconscious influences on direct tasks appear to be entirely bidirectional (cf. Katz, 2001; see Snodgrass et al., 2004, pp. 858-859, 863). For example, in the pop/look experiments (e.g., Snodgrass \& Shevrin, 2002), overall identification was at chance (i.e., no unidirectional effect), but the preference $\times$ strategy interaction nonetheless revealed underlying facilitatory and inhibitory effects. Given these and analogous findings (Price, 1990, 2001), bidirectional unconscious influences on detection may also occur, and they might correlate negatively with unconscious influences on other tasks. At the same time, the lack of evidence for unidirectional unconscious influences on direct tasks, taken together with subjective threshold findings' vulnerability to conscious perceptual explanations, makes it likely that overall above chance (i.e., unidirectional) detection is conscious. Either way, however, negative relationships in the ODT-OIT region are incompatible with skeptical, weakly conscious explanations of unconscious perception index effects.

\section{The Null Sensitivity Problem}

Reingold (2004) denies that the presently reviewed studies' ODT-setting methodologies are significantly improved, arguing instead that they possess flaws comparable to those of earlier work (e.g., Balota, 1983; Fowler, Wolford, Slade, \& Tassinary, 1981; Marcel, 1983) criticized by Merikle (1982), Holender (1986), and others. These earlier critiques identified four such flaws: (1) not targeting chance performance; (2) unequal lighting conditions in the experimental versus threshold-checking phases; (3) failure to examine response bias, which if serious would downwardly bias PC; and (4) too few trials. The first three criticisms address possible systematic biases; the last, random error (i.e., the null sensitivity problem proper). Contra Reingold, however, the present studies addressed all these problems and hence are significantly improved. Possible systematic biases were eliminated - they all targeted chance performance, equated lighting conditions, and both specifically examined and obviated serious response bias. ${ }^{11}$ Random error was also reduced; the presently reviewed studies averaged 94.83 trials, a fourfold increase over the earlier work cited above $(X=$ 23.66). Finally, meta-analytic cumulation allows major progress on random error/null sensitivity concerns; accordingly, it is not necessary, as Reingold suggests, that each study include hundreds of trials.

Reingold (2004) also specifically criticized Snodgrass et al.'s (1993, Experiment 3) detection task, conjecturing that the preceding pseudoexperiment discouraged participants. This is unlikely; ODT conditions throughout all pop/look experiments have rendered them equally frustrating because nothing could be seen in any case. Fur- thermore, the negative relationship between detection and identification in Snodgrass and Shevrin (2002, Experiment 3 ) means that detection performance contained systematic variation, implying that participants do not give up in this paradigm. Also, although Snodgrass et al.'s (1993) detection task indeed provided only modest evidence for ODT status, there is extensive independent corroborating evidence (Snodgrass \& Shevrin, 2002, Experiment 3; Van Selst \& Merikle, 1993, Experiment 3). Moreover, this study's detection task was not representative of the presently reviewed studies as Reingold implies, but rather had the fewest trials of any included.

Finally, Haase and Fisk (2004) suggested that detection might be underestimated due to a lack of practice or feedback. This concern is largely unfounded; all the reviewed direct/indirect experiments (Carr \& Dagenbach, 1990; Dagenbach et al., 1989; Greenwald et al., 1989; Groeger, 1988; Klinger \& Greenwald, 1995) involved practice; Carr and Dagenbach (1990) and Dagenbach et al. (1989) provided feedback as well. Of the reviewed double direct experiments, those of Price $(1990,2001)$ involved practice, and all the pop/look studies (e.g., Snodgrass \& Shevrin, 2002) provided feedback. Furthermore, although practice effects occur with weakly conscious stimuli (e.g., Wolford, Marchak, \& Hughes, 1988), they do not seem to manifest themselves once objective thresholds are satisfactorily estimated (see Snodgrass, 2004). For example, contra Haase and Fisk (2004), Dagenbach et al. (1989) did not find such effects (see Snodgrass et al., 1993, p. 174).

\section{Miscellaneous Criticisms}

Below chance performance and regression analysis. Holender and Duscherer (2004) and Haase and Fisk (2004) worry that below chance detection performance renders certain negative relationship/regression findings questionable. This is not problematic, however, for several reasons. First, when mean detection $d^{\prime}$ is essentially zero (Bernat, Shevrin, \& Snodgrass, 2001; Snodgrass \& Shevrin, 2002, Experiment 3), many negative $d$ 's should occur from measurement error alone; furthermore, when mean detection $d^{\prime}$ is still small and the sample size very large (Greenwald, Klinger, \& Schuh, 1995), measurement error should still produce many negative $d$ 's, including some extreme ones. Second, underlying true conscious perception is more likely with observed positive $d$ 's than with observed negative $d$ 's (Greenwald et al., 1995, pp. 39-40). Accordingly, negative relationships in these experiments are consistent with (very weak) conscious perception override. Third, with participants with little or no conscious detection, bidirectional unconscious influences could produce many negative (i.e., inhibitory) $d$ 's, just as they do with identification in the pop/look paradigm. Furthermore, as described above, such influences could correlate negatively with unconscious influences on other tasks. In contrast, conscious perceptual explanations for negative $d$ 's are untenable, mainly because a stimulus resembles itself more than other response alternatives (see Snodgrass, 2004, for an extended discussion). 
The generalized qualitative differences framework and the nonmonotonic relationship. Reingold (2004) seems puzzled that we criticize the standard qualitative differences approach, yet stress qualitative differences in our framework. Here, Reingold ignores our analysis (Snodgrass et al., 2004, pp. 848, 854), which suggests that qualitative differences must contradict the conscious perception model to carry inferential force, and which formally distinguishes between strong and weak qualitative differences, wherein only the former accomplish this goal. Reingold also worries that inferences relying on the nonmonotonic relationship depend on a single (ODT) data point. ODT effects are certainly critical; however, what happens at the ODT places no logical constraints on what happens elsewhere. Accordingly, that null (vs. comparably sized or bigger) effects typically obtain at the OIT indeed provides independent, converging evidence (i.e., the negative relationship) for ODT effects' reality and moreover alleviates exclusiveness problem concerns. The strong meta-analytic evidence for ODT effects, then, taken together with the null OIT/positive supra-OIT pattern, provides substantial support for the nonmonotonic relationship. Furthermore, contra Reingold, the full U-shaped function has been found whenever conditions have allowed its examination, including in at least seven individual studies (twice each in Dagenbach et al., 1989; Klinger \& Greenwald, 1995; and Price, 1990; once in Greenwald et al., 1995).

\section{Theoretical and Philosophical Objections}

Holender and Duscherer (2004) are so discomfited that the mechanisms for unconscious perception remain to be delineated that they seem prepared to reject empirical evidence out of hand. This puts the theoretical cart before the empirical horse; after all, in the history of science, empirical phenomena are virtually always identified well before detailed explanations become available (e.g., gravity, genetics). Indeed, since nobody yet understands what makes conscious perceptions conscious, it makes little sense to demand analogous explanations for unconscious perception at this time. Rather, now that strong evidence for unconscious perception is at hand, the search for such mechanisms can begin in earnest. At least one general feature is already apparent: Unconscious perceptual processes appear more robust than conscious perceptual processes, in such a way that reducing stimulus intensity degrades the latter more than the former. Indeed, this may be why variations in masking technique seem relatively unimportant. Furthermore, although we cannot pursue this here, in our view Searle's analysis of the relationship between intentionality and consciousness is ultimately merely stipulative. In any event, if these are scientific questions, they must be testable, and whether sizable, reliable ODT effects exist is just such a test.

\section{Concluding Remarks}

The target and present articles provide strong evidence for large, reliable unconscious perceptual effects at the
ODT, and substantial evidence for the nonmonotonic relationship. Although further research is certainly advisable (e.g., on the nonmonotonic relationship, incorporating simultaneous detection and identification methods), the evidence as it stands constitutes a serious challenge to the single-process conscious perception (Holender \& Duscherer, 2004; possibly Haase \& Fisk, 2004; Perruchet \& Vinter, 2002) and subjective threshold (e.g., Merikle \& Daneman, 1998) models and moreover suggests that objective and subjective threshold approaches index qualitatively different phenomena. Accordingly, ODT methods are preferable for investigating phenomenally unconscious phenomena. Subjective threshold methods are suspect for this purpose; instead, they likely index reflectively unconscious phenomena (cf. Block, 2001; Snodgrass, 2002; Snodgrass \& Shevrin, 2002), which are important in their own right. Currently, many researchers do not make this distinction (e.g., Dimberg, Thunberg, \& Elmehed, 2000; Morris, Ohman, \& Dolan, 1998; Whalen et al., 1998).

\section{REFERENCES}

Balota, D. A. (1983). Automatic semantic activation and episodic memory encoding. Journal of Verbal Learning \& Verbal Behavior, 2 22, 88-104.

Bernat, E., Shevrin, H., \& SNodgrass, M. (2001). Subliminal visual oddball stimuli evoke a P300 component. Clinical Neurophysiology, 112, 159-171.

BLOCK, N. (2001). Paradox and cross purposes in recent work on consciousness. Cognition, 79, 197-219.

Bradley, B. P., MogG, K., Millar, N., \& White, J. (1995). Selective processing of negative information: Effects of clinical anxiety, concurrent depression, and awareness. Journal of Abnormal Psychology, 104, 532-536.

CARR, T. H., \& DAGENBACH, D. (1990). Semantic priming and repetition priming from masked words: Evidence for a center-surround attentional mechanism in perceptual recognition. Journal of Experimental Psychology: Learning, Memory, \& Cognition, 16, 341-350.

Dagenbach, D., CARr, T. H., \& Wilhelmsen, A. (1989). Task-induced strategies and near-threshold priming: Conscious influences on unconscious perception. Journal of Memory \& Language, 28, 412-443.

Dimberg, U., Thunberg, M., \& Elmehed, K. (2000). Unconscious facial reactions to emotional facial expressions. Psychological Science, 11, 86-89.

DrAINE, S. C., \& GreEnWALD, A. G. (1998). Replicable unconscious semantic priming. Journal of Experimental Psychology: General, $\mathbf{1 2 7}$, 286-303.

DUNCAN, J. (1985). Two techniques for investigating perception without awareness. Perception \& Psychophysics, 38, 296-298.

Durante, R., \& Hirshman, E. (1994). Retrospective priming and masked semantic priming: The interfering effects of prime activation. Journal of Memory \& Language, 33, 112-127.

EIMER, M. (1999). Facilitatory and inhibitory effects of masked prime stimuli on motor activation and behavioral performance. Acta Psychologica, 101, 293-313.

EIMER, M., \& SCHLAGHECKEN, F. (1998). Effects of masked stimuli on motor activation: Behavioral and electrophysiological evidence. Journal of Experimental Psychology: Human Perception \& Performance, 24, 1737-1747.

FoWLER, C. A., Wolford, G., Slade, R., \& TASsinary, L. (1981). Lexical access with and without awareness. Journal of Experimental Psychology: General, 110, 341-362.

GREenwald, A. G., KLINGER, M. R., \& LiU, T. J. (1989). Unconscious processing of dichoptically masked words. Memory \& Cognition, $\underline{17}_{2}$ $\underline{35-47 .}$

GreEnWAld, A. G., Klinger, M. R., \& Schuh, E. S. (1995). Activation by marginally perceptible ("subliminal") stimuli: Dissociation of 
unconscious from conscious cognition. Journal of Experimental Psychology: General, 124, 22-42.

GROEGER, J. A. (1988). Qualitatively different effects of undetected and unidentified auditory primes. Quarterly Journal of Experimental Psychology, 40A, 323-339.

HAASE, S. J. (1994). A signal detection theory interpretation of "unconscious" perception (Doctoral dissertation, University of Wisconsin, Madison). Dissertation Abstracts International, 55(06), 2422B.

HaAse, S. J., \& Fisk, G. D. (2001). Confidence in word detection predicts word identification: Implications for an unconscious perception paradigm. American Journal of Psychology, 114, 439-468.

HaAse, S. J., \& Fisk, G. D. (2004). Valid distinctions between conscious and unconscious perception? Perception \& Psychophysics, 66, 868-871.

Haase, S. J., Theios, J., \& Jenison, R. (1999). A signal detection theory analysis of an unconscious perception effect. Perception \& Psychophysics, 61, 986-992.

HOLENDER, D. (1986). Semantic activation without conscious identification in dichotic listening, parafoveal vision, and visual masking: A survey and appraisal. Behavioral \& Brain Sciences, 9, 1-23.

Holender, D., \& Duscherer, K. (2004). Unconscious perception: The need for a paradigm shift. Perception \& Psychophysics, 66, 872-881.

JONES, G. V. (1987). Independence and exclusivity among psychological processes: Implications for the structure of recall. Psychological Review, 94, 229-235.

KAHAN, T. A. (2000). Negative priming from masked words: Retrospective prime clarification or center-surround inhibition? Journal of Experimental Psychology: Learning, Memory, \& Cognition, 26, 1392-1410.

KATZ, S. (2001). Bidirectional experimental effects. $\underline{\text { Psychological }}$ Methods, 6, 270-281.

KLINGER, M. R., \& GREENWALD, A. G. (1995). Unconscious priming of association judgments. Journal of Experimental Psychology: Learning, Memory, \& Cognition, 21, 569-581.

KUNST-WILSON, W. R., \& ZAJONC, R. B. (1980). Affective discrimination of stimuli that cannot be recognized. Science, 207, 557-558.

Macmillan, N. A., \& Creelman, C. D. (1991). Detection theory: A user's guide. New York: Cambridge University Press.

MarCEL, A. J. (1983). Conscious and unconscious perception: Experiments on visual masking and word recognition. Cognitive Psychology, 15, 197-237.

MERIKLE, P. M. (1982). Unconscious perception revisited. Perception \& Psychophysics, 31, 298-301.

MERIKLE, P. M., \& DANEMAN, M. (1998). Psychological investigations of unconscious perception. Journal of Consciousness Studies, 5, 5-18.

Mogg, K., Bradley, B. P., Williams, R., \& Mathews, A. (1993). Subliminal processing of emotional information in anxiety and depression. Journal of Abnormal Psychology, 102, 304-311.

Mogg, K., Kentish, J., \& Bradley, B. P. (1993). Effects of anxiety and awareness on colour-identification latencies for emotional words. $\underline{B e-}$ haviour Research \& Therapy, 31, 559-567.

MORris, J. S., OHMAN, A., \& DoLAN, R. J. (1998). Conscious and unconscious emotional learning in the human amygdala. Nature, 395, 467-470.

Perruchet, P., \& Vinter, A. (2002). The self-organizing consciousness. Behavioral \& Brain Sciences, 25, 297-330.

Price, M. C. (1990). Processing and awareness of masked stimuli. Unpublished doctoral dissertation, University of Cambridge.

Price, M. C. (2001). Now you see it, now you don't: Preventing consciousness with visual masking. In P. Grossenbacher (Ed.), Finding consciousness in the brain: A neurocognitive approach (pp. 25-60). London: John Benjamins.

REINGOLD, E. M. (2004). Unconscious perception and the classic dissociation paradigm: A new angle? Perception \& Psychophysics, 66, 882887.

Reingold, E. M., \& Merikle, P. M. (1990). On the inter-relatedness of theory and measurement in the study of unconscious processes. Mind \& Language, 5, 9-28.

Rosenthal, R. (1995). Writing meta-analytic reviews. Psychological Bulletin, 118, 183-192.

RoSENTHAL, R., \& RosNow, R. L. (1991). Essentials of behavioral research: Methods and data analysis (2nd ed.). New York: McGraw-Hill.

SNODGRAss, M. (2002). Disambiguating conscious and unconscious in- fluences: Do exclusion paradigms demonstrate unconscious perception? American Journal of Psychology, 115, 545-580.

SNODGRASS, M. (2004). The dissociation paradigm and its discontents: How can unconscious perception or memory be inferred? Consciousness \& Cognition, 13, 107-116.

SNODGRASS, M., BERNAT, E., \& SHEVRIN, H. (2004). Unconscious perception: A model-based approach to method and evidence. Perception \& Psychophysics, 66, 846-867.

SNODGRASS, M., \& SHEVRIN, H. (2002). Unconscious inhibition and facilitation at the objective detection threshold: Replicable and qualitatively different unconscious perceptual effects. Manuscript submitted for publication.

SnOdgrass, M., Shevrin, H., \& KopKa, M. (1993). The mediation of intentional judgments by unconscious perceptions: The influences of task strategy, task preference, word meaning, and motivation. Consciousness \& Cognition, 2, 169-193.

ThOMAS, J. P. (1985). Detection and identification: How are they related? Journal of the Optical Society of America A, 2, 1457-1467.

Van Selst, M. \& Merikle, P. M. (1993). Perception below the objective threshold? Consciousness \& Cognition, 2, 194-203.

Whalen, P. J., Rauch, S. L., Etcoff, N. L., McInerney, S. C., Lee, M. B., \& JeNIKE, M. A. (1998). Masked presentations of emotional facial expressions modulate amygdala activity without explicit knowledge. Journal of Neuroscience, 18, 411-418.

Whittlesea, B. W. A., \& PRICE, J.R. (2001). Implicit/explicit memory versus analytic/nonanalytic processing: Rethinking the mere exposure effect. Memory \& Cognition, 29, 234-246.

Wolford, G., MarchaK, F., \& Hughes, H. (1988). Practice effects in backward masking. Journal of Experimental Psychology: Human Perception \& Performance, 14, 101-112.

Wong, P., Bernat, E., S Nodgrass, M., \& Shevrin, H. (in press). Event-related brain correlates of associative learning without awareness. International Journal of Psychophysiology.

\section{NOTES}

1. For descriptions of the various models, see Snodgrass et al. (2004, pp. 846-849, 853-857).

2. In our view, these positions collectively amount to defending the subjective threshold model (see Snodgrass et al., 2004, pp. 847-848. In a review of an earlier version of our reply, however, Reingold objected to this construal of his position. For reasons of space, we cannot pursue this issue further here; accordingly, for now we simply note this disagreement and have refrained from characterizing Reingold's position in this way in this reply.

3. Except for very highly speeded paradigms (e.g., Draine \& Greenwald, 1998; Eimer, 1999; Eimer \& Schlaghecken, 1998); for reasons of space, we cannot discuss these in this reply.

4. Reingold (2004, p. 886) worries that the nine ODT investigations constitute a "very meager yield for 15 years of research." There are more that we did not discuss for reasons of space-for example, Bernat, Shevrin, and Snodgrass, 2001; Bradley, Mogg, Millar, and White, 1995; Mogg, Bradley, Williams, and Mathews, 1993; Mogg, Kentish, and Bradley, 1993; Wong, Bernat, Snodgrass, and Shevrin (in press). Furthermore, as Holender and Duscherer (2004) have noted, in recent years most researchers have shifted to computer-administered experiments; computer monitors are generally too slow for achieving the ODT.

5. For Groeger (1988) and Price (1990), $d$ was estimated from other information. For Groeger, cell means estimated from Figure 2 (p. 335), together with the $F$ value for the group $\times$ prime-target relationship effect (p. 334), allowed derivation of the relevant $S D$ (the denominator of $d$ ); the numerator of $d$ came from the ODT group's semantic versus phonological difference score. For Price (1990), $d$ s were derived from $t$ tests performed on correlated variabilities (Rosenthal \& Rosnow, 1991, p. 337). Semantic classification variabilities came from Price's Tables 7.2 and 7.7 (pp. 145 and 158); in each case, the average variability for the two lowest SOAs (at the ODT; see pp. 143 and 157) were compared with the average variability for the next two highest SOAs (where detection exceeds chance). The correlation between variabilities was unknown and was conservatively assumed to be zero (cf. Rosenthal \& Rosnow, 1991, p. 337). 
6. Groeger (1988) and Greenwald et al. (1989) used 2IFC detection tasks; accordingly, their $S D$ s were upwardly adjusted by the square root of two (cf. Macmillan \& Creelman, 1991).

7. Specifically, in Dagenbach et al. (1989, Experiment 4) and Carr and Dagenbach (1990), detection recheck performance was 50.5\% and $49.8 \%$; in Greenwald et al. (1989, Experiments 2 and 3), it was $51.4 \%$ and $52 \%$; and finally, in Snodgrass and Shevrin (2002, Experiment 3), Snodgrass et al. (1993, Experiment 3), and Van Selst and Merikle (1993, Experiment 3 ), detection was $50.88 \%, 49.38 \%$, and $49.3 \%$, respectively. Greenwald et al.'s (1989, Experiment 1) procedure was even more conservative than their latter two experiments and actually ensured that detection performance was below chance (p. 37).
8. In Snodgrass and Shevrin (2002, Experiment 3), participants provided both detection and identification; hence, this is one of the 10 experiments for which both measures were available.

9. For example, detection for the worst performing quartile in Kahan's (2000) Experiment 1 was 77\% (p. 1407). Similarly, free prime identification in Experiment 2 was a hefty $50 \%$ or so (p. 1402).

10. Sometimes negative relationships between the two indexes can even reflect conscious influences on both tasks - for example, when retroactive priming is active (Durante \& Hirshman, 1994; Kahan, 2000). However, these experiments were above the OIT; below the OIT, conscious/unconscious explanations are untenable (see also Snodgrass et al., 2004, pp. 855-856). 11. A detailed account is available from the first author upon request.

(Manuscript received December 24, 2003;

revision accepted for publication February 20, 2004.) 